\title{
Presença de Aedes (Stegomyia) albopictus (Skuse) na cidade de São Pau- lo - SP, Brasil
}

\section{Prevalence of Aedes (Stegomyia) albopictus (Skuse) in the city of S. Paulo - SP, Brazil}

\author{
Vera Soubihe", José Maria Soares Barata*, Delsio Natal", Antonio I.P. da Costa"
}

Desde 1987 o Aedes albopictus teve sua presença assinalada no meio urbano do Município de São Paulo (SUCEN-Superintendência de Controle de Endemias)

Através de coletas mensais realizadas pela Faculdade de Saúde Pública da USP para avaliação da fauna e atividade de mosquitos (Diptera: Culicidae), na área do Parque Engenheiro Goulart (Zona Leste da cidade de São Paulo, próxima à Rodovia dos Trabalhadores), foram encontradas larvas e um exemplar adulto de Aedes albopictus (Skuse).

As larvas foram coletadas nos seguintes criadouros: um vaso sanitário abandonado em área descoberta e na área do depósito de material do setor de ambientação animal, em depressões na lataria de veículos abandonados, da Polícia Florestal (02 e 18/07/1991). O único exemplar adulto foi coletado em armadilha CDC no ambiente peridomiciliar no periodo entre $17: 00$ e $20: 00 \mathrm{~h}(14 / 05 /$ 1991).

\footnotetext{
Departamento de Parasitologia do Instituto de Ciências Biomédicas da Universidade de São Paulo

* Departamento de Epidemiologia da Faculdade de Saúde Pública da Universidade de São Paulo

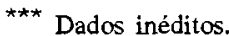

Separatas/Reprints: D. Natal - Av. Dr. Amaldo, 715 - 01255 Sảo Paulo, SP - Brasil.

Publicação financiada pela FAPESP. Processo Saúde Coletiva 91/4994-0
}

A primeira identificação de Aedes albopictus no Brasil foi feita por Forattini ${ }^{2}$ (1986) a partir de exemplares encontrados no Estado do Rio de Janeiro. Sua ocorrência no Estado de São Paulo, no Município de Areias (Vale do Paraíba), foi relatada por Brito e col ${ }^{1}$ (1986). Também foi referido em Tremembé por Gomes e Marques $^{3}$ (1988).

\section{Referências Bibliográficas}

1. BRITO, A. et al. Primeiro encontro de Aedes (Stegomyia) albopictus (SKUSE) no Estado de São Paulo, Brasil. Rev. Saúde públ., S. Paulo, 20: 489, 1986.

2. FORATTINI, O.P. Identificação de Aedes (Stegomyia) albopictus no Brasil. Rev. Saúde públ., S. Paulo, 20: 244-5, 1986.

3. GOMES, A.C. \& MARQUES, G.R.A.M. Encontro de criadouro natural de Aedes (Stegomyia) albopictus (SKUSE), no Estado de São Paulo, Brasil. Rev. Saúde públ., S. Paulo, 22: 245, 1988.

Recebido para publicação em 13/8/1991 Aprovado para publicação em 22/1/1992 